\title{
Ecogenetics of Parkinson's Disease: Prevalence and Environmental Aspects in Rural Areas
}

\author{
André Barbeau*, Madeleine Roy, Gilles Bernier, \\ Giuseppe Campanella, and Suzanne Paris
}

\begin{abstract}
We make use of the unique combination of a homogeneous genetic and racial origin in the rural population of Quebec and the facilities of free and universal access to medical care, to study the distribution of the prevalence of Parkinson's disease in the 9 rural hydrographic regions of the Province. Through 3 different methods of ascertainment, confirmed by two control probes, we demonstrate that the prevalence of Parkinson's disease is of uneven distribution within rural areas. We further investigated the characteristics of the regions of high prevalence. These regions which are predominantly agricultural and areas of intensive market gardening were also the areas with the highest use of pesticides.
\end{abstract}

RÉSUMÉ: Ecogénétique de la maladie de Parkinson: prévalence et aspects environnementaux dans les régions rurales Nous avons tiré profit d'une combinaison unique de facteurs présents dans la population rurale du Québec, soit une population dont l'origine génétique et raciale est homogène et un accès gratuit et universel aux soins médicaux, pour étudier la distribution de la prévalance de la maladie de Parkinson dans 9 régions hydrographiques rurales de cette province. Nous démontrons, à l'aide de 3 méthodes différentes de repérage des cas, confirmées par 2 sondes de contrôle, que la prévalence de la maladie de Parkinson est inégale au sein des régions rurales. Nous avons étudié plus attentivement les caractéristiques des régions de haute prévalence. Comme ces régions sont agricoles et servent à la culture maraîchère intensive, elles sont également celles qui utilisent le plus de pesticides.

Can. J. Neurol. Sci. 1987; 14:36-4I

Our hypothesis on the etiology of Parkinson's disease states that the disorder results from an interaction between environmental determinants and individual genetic susceptibility, both acting on a background of normal aging. ${ }^{1}$ A study from our group has explored one genetic susceptibility component of Parkinson's disease: the hydroxylation of debrisoquine. ${ }^{2}$ In the present paper, we will attempt to identify some of the environmental determinants possibly affecting such susceptible individuals.

Although many authors ${ }^{3,4}$ argue that the prevalence of Parkinson's disease is approximately even throughout the world and does not vary between industrialized countries, ${ }^{5}$ these conclusions are totally unverifiable because of marked differences in epidemiologic methodologies, reporting, diagnosis and access to medical care in the various countries. On the other hand, studies of small regions have often yielded information on the presence of focal environmental risk factors responsible for some forms of parkinsonism; for example manganese in miners and industrial workers, ${ }^{6.7}$ the concentration of calcium and magnesium in drinking water on the Island of Guam ${ }^{8.9}$ or well water in rural south-eastern Saskatchewan. ${ }^{10}$ A possible role for environmental factors is supported by the recent studies on 1-methyl-4-phenyl-1,2,3,6-tetrahydropyridine (MPTP) parkinsonism in man ${ }^{11.12}$ and animals, ${ }^{13.14 .15}$ and the subsequent proposals for a number of possible Parkinson-causing substances in both the external ${ }^{15,16}$ and internal environments. ${ }^{17}$ We therefore reasoned that, in a genetically homogeneous population with equal access to medical care and an even distribution of age groups, any significant regional or focal variation in prevalence could lead to the identification of clues to environmental co-determinants. The province of Quebec, Canada, offers the opportunity for such studies. $98.5 \%$ of its $6,516,112$

From the Department of Neurobiology, Clinical Research Institute of Montreal, University of Montreal

Preliminary data from this study has been presented at the 8th International Congress on Parkinson`s disease (New York, June 10, 1985) and the XXth Canadian Congress of Neurological Sciences (Montreal, June 27, 1985)

Received August 7, 1986. Accepted September 29, 1986

*Deceased March 9, 1986.

Reprint requests to: Dr. Madeleine Roy, Department of Neurobiology, Clinical Research Institute of Montreal, 110 Pine Avenue West, Montreal, Quebec, Canada H 2 W 1 R 7 
inhabitants (June 1st, 1983) are Caucasians (88\% of French origin in rural regions). Universal health insurance (including doctors' fees, hospitalisation and tests, without the possibility of overbilling) has been available for 15 years to every resident, thereby minimizing the major bias of access to care, provided a sufficiently long period of time is studied. It was felt that because of these particular circumstances, accurate, detailed information could be obtained in order to assess and compare the regional prevalence of Parkinson's disease in the province of Quebec.

The present study is a preliminary descriptive epidemiological investigation.

\section{MATERIal AND METhods}

Data on the geographic distribution of parkinsonian patients in the province of Quebec was obtained from three different information pools, and counterchecked by two control probes. The results were plotted by hydrographic region:

1. Data from "La Régie de l'Assurance-Maladie" (Method "A") From the Régie, we obtained a print-out of the registration numbers (including first 3 letters of the name, one initial, date of birth), potal code addresses, and frequency of visits with the diagnosis of Parkinson's disease (I.C.D. CODE 332.0) for all cases seen and reported for the period 1981-1984. No medical service is paid for in Quebec without report of this information by the physicians. From the list, we accepted only cases reported at least twice with the diagnosis of Parkinson's disease and living on prevalence day, June 1st 1983. The average number of reported visits with this diagnosis was 7 per patient during the study period. 5,270 cases of parkinsonism were thus identified and their residence plotted on the map.

2. Data from levodopa sales (Method "B") Levodopa is used almost exclusively for the treatment of Parkinson's disease. It is thus reasonable, as demonstrated in detailed studies by de Pedro and Rosenquist, ${ }^{18.19}$ to use sales data of that drug to estimate the local or regional prevalence of Parkinson's disease. Through the courtesy of Merck Sharp \& Dohme Canada and Hoffman-La Roche Canada, we obtained detailed 1984 local sales data (by city, town, village and postal code) for Sinemet $(R)$, Larodopa $(\mathrm{R})$ and Prolopa $(\mathrm{R})$, including all dose preparations. From previous surveys of movement disorder clinics we had shown that the average daily dose of levodopa prescribed in Quebec was $550 \mathrm{mg}$ (range $450-650 \mathrm{mg} / \mathrm{day}$ ). The levodopa sale figure for each locality (in kilograms of levodopa) was divided by the average yearly consumption per client to obtain the average number of treated patients in that locality. A total of 4,233 cases of Parkinson's disease was thus derived for the province of Quebec. The individual locality results were plotted on the map.

3. Data from death certificates (Method "C") Data on all death certificates where Parkinson is mentioned as an immediate, secondary, related or underlying cause of death, between 1980 and 1984, was obtained from le Ministère des Affaires Sociales du Québec, along with the last known place of residence of the patient. Data was obtained for 388 cases of Parkinson's disease so identified and the last place of residence plotted on the map. 4. Control probe one Since the principal weakness of the above three methods is accuracy of diagnosis, the geographic location results were checked with a smaller sample of 1,303 (943 urban, 360 rural) confirmed cases of Parkinson's disease, living on
June Ist, 1983, from the 4 movement disorder clinics of Montreal and 34 other neurologists practicing within 100 miles of Montreal. All teaching hospitals of the two medical schools of Montreal reported cases and no regional bias was observed in the percentage of neurologists reporting. The individual places of residence of the patients were plotted on a map.

5. Control probe two We surveyed the 77 physicians practicing within one of the rural areas identified as having a high prevalence rate for the disease (see results). The mail survey identified 71 cases of Parkinsonism living within that area (population 412,280) on prevalence day, June 1st, 1983. A subsequent personal visit was made by one of us to confirm diagnosis and analyze a number of variables possibly influencing the results of the data collection methods used above: age distribution, movement in and out of the basin, utilisation of levodopa, reports to the Régie, etc.

6. Hydrographic regions We have chosen to report our results on prevalence by hydrographic region, rather than census or electoral region, because we believe this approach better reflects environmental factors, since all pollutants (whether from the air, rain, industrial production, waste disposal, spraying, . . .) eventually end-up in the soil and its surface or underground water deposits where we could eventually measure them. There are 428 river drainage basins in the province of Quebec, regrouped into 10 major hydrographic regions. ${ }^{20}$ The population of each municipality within these regions has been established for June Ist, 1983. ${ }^{21}$ In the present study, data from region 10 (NouveauQuébec) was combined with that from region 9 because of the small population and large areas involved.

7. Other data Data on agriculture ${ }^{22.23}$ and sales of pesticides ${ }^{24.25}$ has been obtained from le Ministère de l'Environnement du Québec, Statistiques Canada, le Ministère de l'Agriculture du Québec. Population characteristics were derived from the 1981 census data of Statistics Canada. ${ }^{26}$ Median age and percentage of population over the age of 45 for each basin were compared. Spearman correlation coefficients were calculated according to Colton. ${ }^{27}$

\section{RESULTS}

The population of Quebec $(6,516,112$ on June 1st, 1983) is divided almost equally between metropolitan (defined as cities with a population larger than 50,000 - total $3,078,743$ ) and rural areas $(3,437,369)$. In this paper we will focus on the results obtained in the 9 rural hydrographic basins of the province. As seen in Figures 1 and 2, and in Table 1, there is a marked variability in the prevalence rate of Parkinson's disease (per 1,000 population) between the various rural regions, with all three methods of ascertainment. The cut-off points for prevalence rates in these figures have been arbitrarily chosen for greater visual impact of the results, but do not influence the rank correlation values. Even if we exclude region 07 and 09 because of their distance away from metropolitan centers and neurological expertise, the variability observed between the low prevalence regions $(06,08)$ and the high prevalence region (03) is 2.8 fold for all three methods. Region 03 has an observed prevalence of Parkinson's disease on the average $80 \%$ above the mean for all other rural regions, and very close to that of industrialized metropolitan areas. Rank order coefficients for all three methods and for the 9 regions, are highly significant ( $r$ $=0.83,0.95$, and 0.85 respectively). By all methods of 


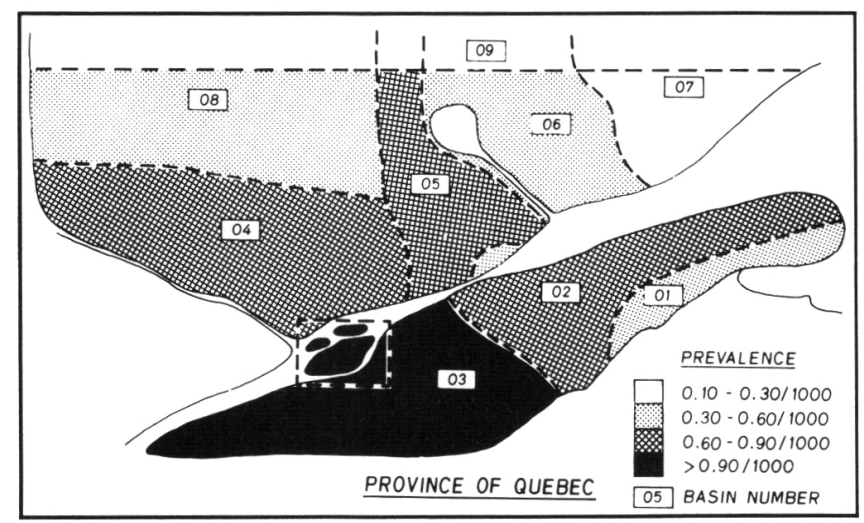

FIGURE 1 DISTRIBUTION OF 5270 CASES OF PARKINSON'S DISEASE BY HYDROGRAPHIC BASINS AS REPORTED TO THE "REGIE"

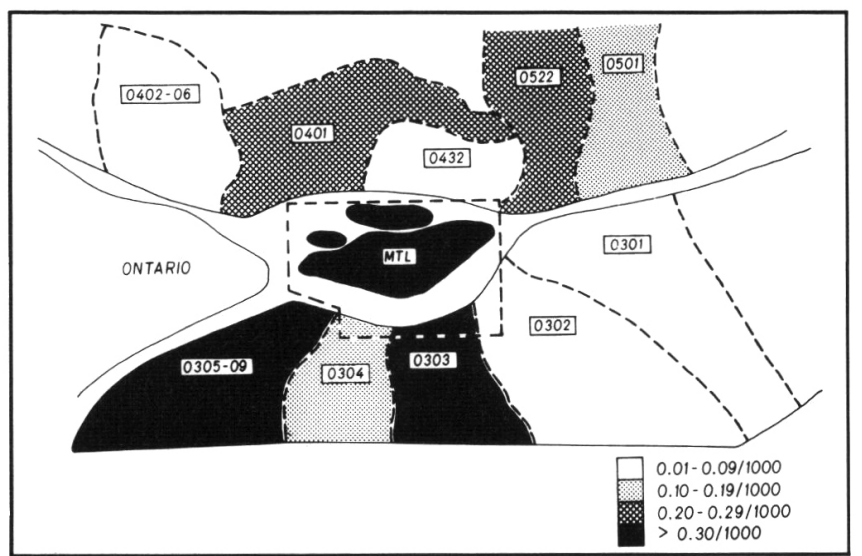

FIGURE 2 DISTRIBUTION OF 1303 CASES OF PARKINSON'S DISEASE CONFIRMED BY NEUROLOGISTS IN MONTREAL METROPOLITAN AREA

Table 1: Prevalence of Parkinson's Disease in Quebec

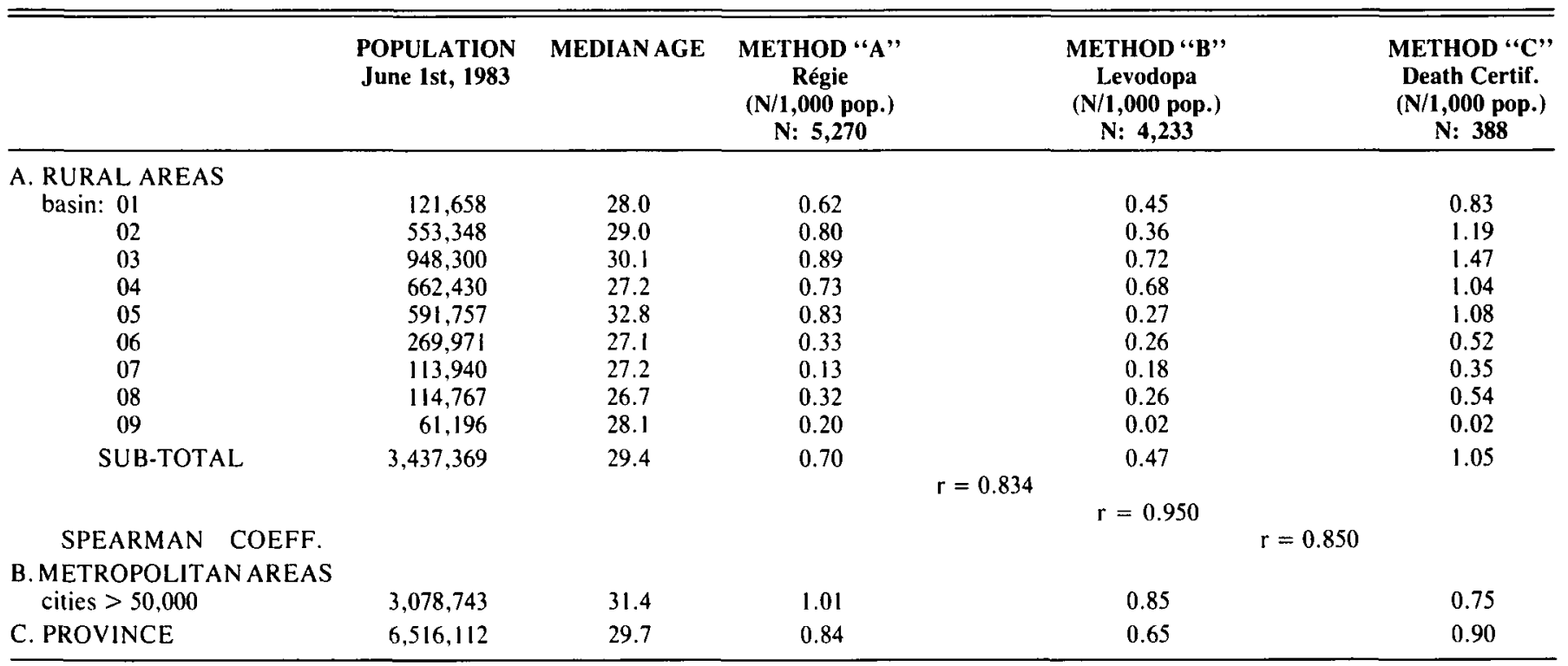

ascertainment, region 03 thus has the highest prevalence of Parkinson's disease.

This finding has been confirmed in the probe study on the site of residence of 1,303 cases of Parkinson's disease whose diagnosis was definitely confirmed by qualified neurologists from Montreal. It is seen in Figure 2, that for the 360 rural cases confirmed by neurologists, the highest prevalences were found in the basins of the Yamaska River (0303) and of the Chateauguay River (0309), both within the high prevalence hydrographic region 03. All other 8 sub-regions within a 100 miles radius from Montreal have equal access to neurological services, but clearly lower prevalences of Parkinson's disease.

\section{Discussion}

The above results indicate that Parkinson's disease in the rural areas of Quebec is not evenly distributed, clearly contradicting inferences from previous prevalence studies ${ }^{3.4}$ and recent statements. ${ }^{5}$ One region of high prevalence out of the possible 9 was identified in the racially and socio-economically homogeneous population investigated. It is important to note that all methods of ascertainment used in this study coincide in their results. Before trying to look for specific determinants within these regions, it is important to discuss the validity of the data, which rests on a number of assumptions:

a. Age and genetic composition of the population studied The median age of the population of Quebec is 29.7 years. There is no significant difference between this figure and that for any specific rural region studied (Table 1). The same conclusion can be made for the sub-regions $(0303,0309)$. Indeed, analysis of the 5 year-group distribution data for each region, from the 1981 census, ${ }^{26}$ shows no significant difference between basins. The results quoted (except for the Levodopa data) were all ageadjusted to the Quebec 1983 population. The ethnic composition of the rural population of Quebec is homogeneous, since $88 \%$ are of French Canadian origin, i.e. descendants of French settlers having migrated to Quebec before 1760. Most of the other $12 \%$ are of English ancestry and live mainly in cities and towns. Therefore these two factors are of importance for the accuracy of our study, but do not influence the relative regional results. Similar conclusions can be reached regarding socioeconomic status.

b. Availability and access to medical care Universal and free access to medical care is the rule under Quebec's Health System. 
The physician to population ration is $1 / 520$ for the province, and never exceeds $1 / 822$ in the most distant regions $(07,09)$. Although in distant areas the lower number of physicians may contribute to a delay in care, it does not significantly influence access to care over the 4 year period of observation. However, because of the absence of neurologists in these two areas, the figures observed are probably too low and have been excluded from the statistical analyses and conclusions. The other 7 hydrographic regions have satisfactory access to neurological care (there are 135 practicing neurologists in the province).

c. Quality and completeness of the reporting These factors were verified in the control rural region studied (0307-0309) whose population is 41,280 . Of the 71 cases of Parkinsonism reported to us by 76 of the 77 physicians practicing in the region, $67(94.4 \%)$ were indeed identified in the Régie list of "Parkinson's disease" cases, over the period 1981-1984. During that period of study, $61 \%$ of the cases of verified Parkinson's disease (movement disorder clinics) known to have died, had the diagnosis actually recorded on the death certificate.

d. Mobility of the population This was estimated by sample questionnaire in the control region (0307-0309) and found to be $1.8 \%$ per year for the present population, and was calculated to be $0.7 \%$ per year over the last 20 years. This figure probably reflects the situation in most rural areas of Quebec, and indicates relative stability of residence.

e. Accuracy of diagnosis This is, of course, the most important requirement for good prevalence studies. Diagnosis for the neurologist data pool and for the control region studies was based on the following criteria: (1) presence of at least 2 of the following signs: tremor, rigidity, akinesia or postural difficulties; (2) absence of stroke, trauma to the head, oculogyric crises, encephalitis or blepharospasm; (3) absence of a history of phenothiazine, butyrophenone, reserpine or illegal drug use; (4) absence of known history of exposure to manganese or carbon monoxide.

In the control region (0307-0309), a 20\% diagnostic error rate was found. Only 57 of the 71 identified cases were confirmed as Parkinson's disease with the above criteria. 10 were in fact essential tremor, 3 multi-system atrophies and 1 hyperthyroidism with tremor. This error rate is similar to that $(19 \%)$ found in 630 new patients from all regions of the province referred to our own movement disorder clinic with the presumed diagnosis of "Parkinsonism". Correction for this error factor would have to be made to estimate true prevalence rates, but no major variations were noted between hydrographic regions among the referred cases from different areas of the province to influence prevalence rates.

In the same control region (0307-0309), 84\% of the 67 cases reported to the Régie were receiving one of the levodopa preparations, a figure similar to the experience of other investigators. A $16 \%$ correction for this factor to the figure derived from levodopa sales would give an estimated number of 4,910 cases of Parkinson's disease in the province, a figure not significantly different from the 5,270 actually identified by the Régie.

Since we are estimating prevalence rates, we should also know about duration of the disease, assuming a uniform incidence rate during the short period of study. In the control probe area, situated within hydrographic region 03 , duration of the disease in verified living cases was $9.2 \pm 1.2$ years, a figure identical to that of the 970 cases seen in the 4 movement disorder clinics in Montreal $(9.3 \pm 1.1$ years). Duration of the disease for the neurologist-confirmed cases known to have died was $14.1 \pm 3.2$ years. There were no variations from rural region to rural region, in the latter cases.

In summary, the figures for prevalence of Parkinson's disease obtained for the 9 rural hydrographic regions of Quebec are valid and reliable within error rates that can be estimated, and they can be used for comparative studies such as the ones reported here. The region used as control for estimation of the variables (region 0307-0309) is representative of the other rural basins in Quebec for age distribution, ethnic origin and socioeconomic level. This data, however, should not be used for comparative studies with published results from other countries, since different methodologies have often been used. Our results therefore clearly point out that: (1) the prevalence of Parkinson's disease between rural regions is not even, contrary to previous assumptions; ${ }^{3,4}(2)$ one rural hydrographic region of Quebec (region 03) is consistently found to have the highest prevalence rate for Parkinson's disease.

It is thus important to better describe this region so that its specific characteristics can be identified:

a. Hydrographic region 03 The primary characteristic of region 03 is that it is almost exclusively agricultural. In fact, $70-80 \%$ of the commercial production of most vegetables in the province takes place in basins 0303 to 0309 within that region also called the "Garden of Quebec". ${ }^{21}$ The region is also known for its apple orchards. Region 03 supplies most of the province and even neighboring provinces or states with vegetables and apples. Consistent with this commercial-agricultural function, the region is also, by far, the largest consumer of pesticides. In 1982 only, $1,561,189 \mathrm{~kg}$ of various pesticides ${ }^{24}$ were sold in that region $(178,774 \mathrm{~kg}$ of carbamates, $59 \%$ of the provincial total; 5,395 of quaternary ammonium products, $34 \%$ of the total; $370,443 \mathrm{~kg}$ of triazines and triazoles, $64 \% ; 76,881 \mathrm{~kg}$ of organophosphates, $59 \%$ ).

It can be seen in Figure 3 that a significant correlation $(r=$ 0.967 ) exists between pesticide use and the prevalence of Parkinson's disease in the 9 rural regions. Even though evidence exists that some pesticides (particularly ammonium products and organophosphates) can cause neurological and even extrapyramidal symptoms in animals, ${ }^{15,28-32}$ the observation we report here as a risk factor should not be interpreted as proof of causal relationship. Any number of other factors associated

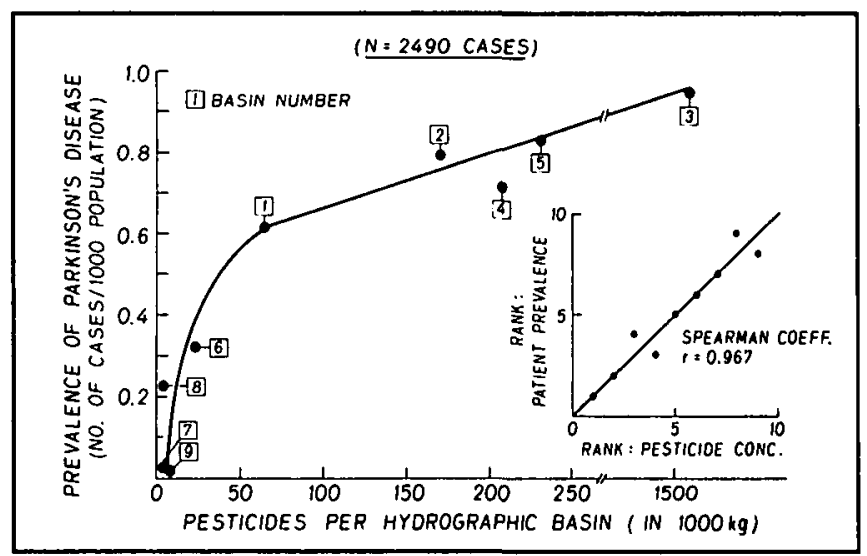

FIGURE 3

CORRELATION BETWEEN THE OBSERVED PREVALENCE OF PARKINSON'S DISEASE IN RURAL AREAS AND THE USE OF PESTICIDES IN QUEBEC 9 MAJOR HYOROGRAPHIC BASINS 
with rich agricultural land (such as soil composition; water content of calcium and minerals, fertilizers, sprays of various kinds, manure, water acidity level, . . . ) should be scrutinized. It should also be stated that previous to the use of present day synthetic pesticides, farmers in the region had long been utilizing potent arseniates as herbicides ("vert de Paris"). The latter substances are known to affect catalase and peroxidase systems, both enzymes important in the defense against free radicals, and therefore the prevention of substantia nigra damage.'

The possible link with pesticides, and particularly herbicides, takes on added significance when similarities between Paraquat $(R)$ and the MPTP metabolite MPP ${ }^{+}$are considered, ${ }^{15.16}$ and when it is recognized that most pesticides are detoxified by hepatic monooxygenase enzymes of the $\mathrm{P}_{450}$ family. ${ }^{28}$ We have indeed recently demonstrated ${ }^{2}$ that $2 / 3$ of parkinsonian patients have a partial or complete defect in the activity of one such $\mathrm{P}_{450}$ enzyme function, the hydroxylation of debrisoquine. These subjects could therefore be susceptible to the toxic effects of many substances. ${ }^{29.30,31}$ In addition, susceptible individuals with deficient $P_{450}$ function whose remaining enzymes are induced to their limit by exogenous xenobiotics such as herbicides, ${ }^{28}$ would be unable to properly detoxify a number of endogenous toxic compounds utilizing the same $\mathrm{P}_{450}$ system. Some of these compounds, like n-methyl-nicotinamide, (Poirier and Barbeau, FFBS Letter, in press) could cause damage to cell respiration. Thus it is not absolutely necessary for an environmental trigger factor to itself reach the substantia nigra to be toxic to it, particularly if the detoxifying defense system in the liver is already impaired genetically or by competitive inhibition.

In conclusion, because of the genetic homogeneity of the rural population of Quebec, and because the health care system in the province provides general and free access to medical care, we were able to take advantage of this situation and demonstrate that the distribution of Parkinson's disease between rural regions in Quebec is uneven, contrary to the inferences from previous authors. This uneven pattern is not due to age characteristics of the population, variations in access to medical care or difference in reporting. We were able to identify one high prevalence hydrographic region, whose characteristic is to be agricultural. Descriptive (individual ecogenetic profiles) and analytical case-control epidemiological studies have been undertaken in these regions to further identify the role of these and other environmental determinants, but reporting of the present observations at this time was thought necessary so that the difficult studies required to verify the findings and search for risk factors in similar regions could also be undertaken in other countries.

\section{ACKNOWLEDGEMENTS}

Supported in part by grants from the Medical Research Council of Canada (MT-4938), the W.G. Weston Foundation and La Fondation Parkinson du Québec. Thanks are due to all the physicians who participated in this study and particularly Drs. S. Gauthier. Y.. Duchastel and A. Morton; to members of La Régie de l'Assurance-Maladie du Québec (Dr. A. Mockle, Mr. D. Carmichael, Mr. G. Bard); Le Ministère des Affaires Sociales (Mrs. D. Delisle); Le Ministère de l'Environment (Mr. R. Saint-Jean, Mr. J. Paré): Le Ministère de I'Industrie, du Commerce et du Tourisme (Mr. R. Roy, Mr. Y. Durand); to Merck Sharpe \& Dohme Canada (Mr. C. Blouin and Mr. G. Boisvert); to Hoffmann-La Roche Canada (Mr. D.W. Hardy); to Statistics Canada; to Agriculture Québec (Mr. P. Noreau) and to the many persons concerned with environmental problems who provided advice and information: to Isa- belle Morin, Monique Paradis and Oswald Taliana for illustrations and to Nicole Guay-Poirier for the manuscript.

\section{REFERENCES}

1. Barbeau A. Etiology of Parkinson's disease: A research strategy. Can J Neurol Sci 1984: 11: 24-28.

2. Barbeau A, Cloutier T, Roy M, Plasse L, Paris S, Poirier J. Ecogenetics of Parkinson's disease: The 4-hydroxylation of debrisoquine. Lancet 1985: ii: 1213-1216.

3. Marttila RJ, Rinne UK. Epidemiology of Parkinson's disease An overview. J Neurol Transm 1981; 51: 135-148.

4. Kurland LT. Epidemiology: Incidence, geographic distribution and genetic considerations. In: Fields WS (editor): Pathogenesis and Treatment of Parkinsonism. Springfield. Il, Charles C Thomas, Publisher, 1958; pp. 5-49.

5. Eldridge R. Rocca WA. The clinical syndrome of striatal dopamine deficiency: Parkinsonism induced by MPTP. New Engl J Med 1983; 313: 1159-1160.

6. Cotzias GC. Manganese, melanin and the extrapyramidal system. J Neurosurg 1966; 24: 170-180.

7. Barbeau A. Manganese and extrapyramidal disorders. Neurotoxicology 1984; 5: 13-36.

8. Yanagihara R, Garruto RM, Gajdusek DC et al. Calcium and Vitamin D metabolism in Guamanian Chamorros with amyotrophic lateral sclerosis and parkinsonism-dementia. Ann Neurol 1984: 15: 42-48.

9. Garruto RM, Yahagihara R, Gajdusek C. Disappearance of high incidence amyotrophic lateral sclerosis and parkinsonism-dementia on Guam. Neurology 1985; 35: 193-198.

10. Rajput AH, Stern A, Christ A, Laverty W. Etiology of Parkinson's disease: Environmental Factor(s). Neurology 1984; 34(3): 207.

11. Langston JW, Ballard P, Tetrud JW, et al. Chronic parkinsonism secondary to intravenous injection of meperidine analogues Science 1983; 219: 979-980.

12. Barbeau A, Roy M, Langston JW. Neurological consequence of industrial exposure to 1-methyl-4-phenyl-1,2,3.6-tetrahydropyridine. Lancet 1985; i: 747.

13. Burns RS, Chiueh CC, Markey SP, Ebert MH. Jacobowitz DM, Kopin IJ. A primate model of Parkinsonism: Selective destruction of dopaminergic neurons in the pars compacta of the substantia nigra by N-methyl-4-phenyl-1,2,3,6-tetrahydropyridine. Proc Natl Acad Sci USA 1983; 80: 4546-4550.

14. Barbeau A, Dallaire L, Buu NT, et al. New amphibian models for the study of 1-methyl-4-phenyl-1,2,3.6-tetrahydropyridine (MPTP). Life Sci 1985; 36: 1125-1134.

15. Barbeau A, Dallaire L, Buu NT, et al. Comparative behavioral, biochemical and pigmentary effects of MPTP. MPP ${ }^{+}$and Paraquat in Rana Pipiens. Life Sci 1985; 37: 1529-1538.

16. Snyder SH. D'Amato RJ. Predicting Parkinson's disease. Nature 1985; 317: 198-199.

17. Testa B, Naylor R, Costall B, Jenner P. Marsden CD. Does an endogenous methylpyridinium analogue cause Parkinson's disease? J Pharm Pharmacol 1985; 37: 679-680.

18. de Pedro J, Rosenqvist U. Tracers for Paralysis Agitans in epidemiological research. I. Analysis of Swedish drug-use registrers and tracer selection. Neuroepidemiology 1984: 3: 82-96.

19. de Pedro J, Rosenqvist U. Tracers for Paralysis Agitans in epidemiological research. II. A model for indirect estimation of the prevalence of the disease. Neuroepidemiology 1984:3: 97-107.

20. Anonymous. Carte des bassins hydrographiques de Québec. Bureau d'étude sur les substances toxiques. Gouvernement du Québec, service de protection de l'environnement, Québec 1984.

21. Joe S. Estimation de la population des municipalités du Québec au ler juin 1983. Bureau de la statistique du Québec. Québec 1984; pp. 1-142.

22. Labrecque J, Thibault $M$. Atlas de l'agro-alimentaire du Québec. 2e édition, Ministère de l'Agriculture. Québec 1978: p. 1-70.

23. Anonymous. 1981 Census of Canada. Agriculture-Quebec. Catalogue 96-906. Statistics Canada. Ottawa 1982.

24. Reiss R, Perron F, Paré J, et al. Les pesticides au Québec en 1982. Environnement-Canada et Environnement-Québec. Québec 1984: pp. 1-134. 
25. Anonymous. Parcs industriels du Québec. Ministère de l'Industrie, du Commerce et du Tourisme. Québec 1984; pp. 1-76.

26. Anonymous. 1981 Census of Canada. Population, occupied private dwellings, private households, census families in private households. Selected characteristics: Quebec. Catalogue 93-917. Statistics Canada, Ottawa 1982.

27. Colton T. Statistics in medicine. Boston, Little, Brown \& Co 1974; pp. 1-372.

28. Kulkarni AP, Hodgson E. The metabolism of insecticides: the role of monooxygenase enzymes. Ann Rev Pharmacol Toxicol 1984; 24: 19-42.

29. Ghali GZ, Hollingworth RM. Influence of mixed function oxygenase metabolism on the acute neurotoxicity of the pesticide chlordimeform in mice. Neurotoxicology 1985; 6: 215-238.
30. Wong TK, Everson RB, Hsu S-T. Potent induction of human placental monooxygenase activity by previous dietary exposure to polychlorinated biphenyls and their thermal degradation products. The Lancet 1985; i: $721-724$.

31. Agrawal AK, Tilson HA, Bondy SC. 3,4,3', $4^{\prime}$-tetrachloro-biphenyl given to mice prenatally produced long-term decreases in striatal dopamine and receptor binding sites in caudate nucleus. Toxicol Lett 1981; 7: 417-424.

32. Seegal RF, Bush B, Brosh KO. Polychlorinated biphenyls induce regional changes in brain norepinephrine concentrations in adult rats. Neurotoxicol 1985; 6: 13-24. 